find an exacerbation of theim all, and be obliged to resume at this, at whatever risk of credit for consistency of character, some treatment, the suspension of which he had ordered at the last visit. Such and other annoying features were inscribed upon the past epidemic, and the practitioner had unusual demands nade upon his resolution, by the occurrence of all the possible phases of the febrile type, with mutability and irregularity. Fallacies, the pushing of rules too rigorously, and a tendency to relapse during apparently promising convalescence, along with the insidious features of concestive complications and nervous anomalies, were the stumbling blocks against which he might often stake at once his patient's chance of restoration and his own reputation.

( $T$ o be continued.)

\section{CASES OF INJURY OF THE HEAD.}

By Jonathan Toogood, M.D.,

Licentiate of the Royal College of Physicians, Fellow of the Royal College of Surgeons, and Consulting Physician and Surgeon to the Bridgewater Infirmary.

\section{Case 1.}

Mr. M. I., a very strong man, aged 32 , was thrown from his horse, on Thursday night, May 16th, and received a violent blow on the left side of his head and shoulder. He was stunned by the fall, and lay on the road insensible for some time. He was removed to a house about two miles distant, where, after some time, he recovered his senses and walked up stairs with a little assistance. No injury could be discovered on examining the head. He was bled to thirty ounces, took some active purgative, and was directed to be kept quiet.

Un the following evening I visited him in consultation with Mr. Board, who saw him on the receipt of the accident. He was in a state of abstraction, but not insensible ; was easily roused, and answered questions rationally; his head was fixed to the pillow; the pupils were natural and readily contracted; there was great intolerance of light; the pulse was frequent, but natural, neither full nor hard ; the respiration and skin natural; he was very irritable and restless, and complained of much pain in the head; the tongue was furred and loaded, and there was frequent sickness; be was derf in the left ear, but heard perfectly in the right ; there had been no discharge of blood froin either. The head was carefully examined again, but no injury could be detected. He was bled freely and the carthartic medicine repeated.

On the Sunday evening I received the following report from his surgeon :- "The carthartic inedicine acted powerfully, by which he was much relieved, and passed a quiet night. On Saturdry, the pain in the head and morbid sensibility of the retina had much abated. He got out of bed every time the medicine acted without asssistance, but when in the erect posture required to have his head supported, and it is wortlyy of remark, that every time he got up, a few drops of blood fell from his nose; he took neutral salts and other febrifuges, which acted properly, and strict antiphlogistic regimen was obseived. The pulse was 90 and small, the intellect unimpaired, and be gave signs that his memory was us streng, as ever; conversed rationally, and with his recustomed cheerfulness. On Sunday his friends were all convinced of his amendment; his head was still more relieved, and the bowels open. In the evening, however, his face became flushed, and the pulse faller and harder. Thirty ounces of blood were taken from his arm, which sank the pulse and greatly relieved him. In compliance with his urgent solicitation a blister was applied to the nape of the neck."

On Monday I visited him again at nine a.m. He had passed a quiet night, got out of bed twice without assistance, was very tranquil, but had not been sensible at times. He complained a little of his head; the pupils were natural, and contracted very readily; pulse regular, but frequent; respiration and skin natural. He felt weak, and mentioned a tíngling sensation and numbness of the left arm, which came on at three in the morning. He was perfectly sensible, and not only related all the circumstances of the accident, but referred to a former one which occured some years before. On minutely examining the head, he shrunk on pressure being made over the temporal muscle of the right side, and on increasing the pressure, be immediately had a violent epileptic fit, from which be soon recovered and became as sensible as before, and continued relating the history of his former accident, taking it up at the point he had left it on the occurrence of the fit.

Another trial was made by pressing very firmly on the same spot, whieh did not however, produce a similar effect, although he shrunk from it, as it gave him pain. At eleven o'clock lie had another fit. At twelre he expressed himself as feeling much better, raised bis head from the pillow and shook it, saying that he felt no pain, but only a weight on his forehead; he complained still of the numbness and tingling of the left arm and hand. At one he had another severe fit, and as soon as he was recovered from it he was bled. Soon after this he had another; after which he lay motionless on his back, the fits succeeding each other at intervals of a quarter of an hour until three o'clock, when he expired. The pupils contracted on exposure to light, and he gave tokens of sensibility ten minutes before his death.

On denuding the cranium, not the slightest injury could be discovered. The right temporul nuscle was removed, but no fracture could be detected at the part on which pressure seemed to have produced the epileptic fit. The left temporal muscle was black with extravasated blood, from the blow which seemed to have been received on this part. The vessels of the dura mater were loaded with blood, and on removing it, the right hemisphere was found enveloped in coagulated blood: " On removing the hair two fractures were immediately visible-one on the right side, extending about two inches upwards and downwards in a right line through the squamous suture; the other running through the centre of the mastoid process and petrous portion of the temporal bone, to the centre of the base of the skull. A piece of tl:e petrous portion, about the size of a pea, was entirely detached, but not displaced so as to cause pressure.

\section{Case II.}

William Govier, aged 44, was thrown from his horse 
on the night of November 16th, 1826, and sustained a severe fracture of the skull. He walked with assistance to a cottage at some distance; although insensible he soon recovered his senses and retained them. On a careful examination of the nature of the injury, it was found to be very extensive', the fracture running through the anterior superior angles of the parietal bones and upper portion of the frontal bone, immediately over the longitudinal sinus. Several loose portions of bone were driven into the brain to a considerable depth, so that it was a good deal lacerated. It was determined at once to proceed to an operation. Accordingly an angular portion of bone was first removed with Hey's saw, with the intention of raising the depressed pieces; but this was found to be impracticable, until a larger portion was removed by a circular saw, which gave plenty of space for detaching the numerous broken pieces. One very large portion was driven down under the frontal bone, inmediately over the longitudinal sinus, the removal of which was effected with much diffiçulty, and followed by profuse bleeding from the sinus. This, howerer, was completely checked by the introduction of a plug of lint. He was bled freely, and the usual antiphlogistic practice pursued.

His recovery was perfect, although delayed by the supervention of an attack of acute rbeumatism.

\section{Case int.}

Isaac Bevan, aged 15, was knocked down by the vane of a windmill, which was rapidly revolving on a very windy day. The blow was so violent that it broke the wood-work of the frame, and drove the boy forwards to a considerable distance. Being in the neigh? bourhood at the time of the accident, I saw him immediately. There was an extensive laceration "of the sealp, and fracture of the temporal and occipital bone. He was stunned, but not wholly insensible, and had vomited. He was removed to the Bridgewater Infirmary in a cart, a distance of ten miles, six or seven hours after the accident. On enlarging the "wound, the injury was found to be so great, that I considered the case almost hopeless. The bones were broken into many pieces, some of which were completely detached, and driven into the brain, portions of which were discharging from the wound. I removed sixteen pieces, the largest of which was driven down to the base of the skull, and got up with great difficulty.

He remained insensible after the operation, but on the following morning he was free from fever. Although he did not regain his speech or senses until the tenth day, he completely rccovered in a short time without any active treatment.

\section{Case IV.}

John Greenfield, aged 18, a strong, healthy, farmservant, was brought to my house at six in the evening of Monday, the 9th of September, having about two hours before received a kick on the head from a cart-. horse, which knocked him down, but did not stun him, for he, raised himself on his kpees before a man who saw the accident from a short distance could come to his assistance, and was able to describe the manner in which the blow was given, and to tell his name and place of residence. There was a wound over the right eye, which led to a very considerable fracture of the frontal bone. He was quite sensible, complained only of slight pain in the head, and walked some distance to an inn, and was put to bed. He had some stupor, but not in any considerable degree; sickness, which was increased by pressure on the fracture; dilatation of the pupils, which contracted on the approach of a candle; the respiration was natural. As the symptoms were not urgent, a small quantity of blood was taken, and a purgative administered, which was thrown up four hours after, whilst examining the wound, and reinoving some coagulated blood. The pulse was 60 , and intermitted ance in fifteen or twenty beats. He was again bled, and directed to be kept quiet.

Tuesday.-He passed a tolerable night, but.was frequently sick; stupor rather increased; pulse 60 , but more oppressed; respiration rather laborious. On the whole the symptoms are increased, but he got out of bed without assistance during the night to make water. At twelve o'clock I divided the scalp right and left in a semicircular direction, which enabled me to ascertain the nature and extent of the injury. The fracture began about the middle of the frontal bone, and ran across the frontal sinus towards the temporal bone to the extent of nearly two inches. The principal depression was at the sinus; the edges of the bone, particularly towards the orbit, were very jagged, and irregularly broken. I found Mr. Hey's saw extremely useful in remoring the rough edges of the bone, which enabled me to raise several large detached pieces. Eighteen fragments were removed, including the whole frontal sinus. Having carefully removed a considerable quantity of coagulated blood from the dura inater, the scalp was laid down and covered with light dressing. The pulse rose immediately to 86 , and became perfectly regular, and he felt so much relieved that he got qut of bed, stood upright, and put on a clean shirt without any assistance. He was directed to take ten grains of calomel, with an equal quantity of jalap, and afterwards a purgative mixture. At five o'clock his pulse was 65, and there was some stupor, which was relieved by the loss of twenty ounces of blood, when his pulse again rose to 86 .

Wednesday morning, nine o'clock.-Was very restless until three o'clock, after which he slept tolerably. Is perfectly sensible; pulse 82 ; breathing natural; complains of some pain in the head; has not been sick since the operation; no evacuation from the bowels. He was bled, and the calomel and jalap repeated.

Eight o'clock p.m.-Has been freely purged, is hot, restless, and complains of slight pain in the head, but is quite sensible. Pulse 84, hard, and full. - He was bled to the extent of tivelve ounces, and directed to take saline medicine, with tartarized antimony and nitrate of potash.

Thursday, eight a.m.- Has passed a good night and is quite sensible; pulse 72. He was directed to keep quiet and continue the same medicine; but his pulse being full and jarring, at eight o'clock he was bled to eight ounces. At ten he became hot and very restless, vomited, and was delirious, constantly endeavouring to get out of bed. Ten ounces of blood were drawn, and some purgative medicine given, which quieted him until two o'clock a.m., when all the bad symptoms returned, and were again relieved by a repetition of the bleeding and purgative.

Friday morning, nine o'clock.-He is worse in every respect ; appears to be sensible, and puts out his tongue 
when desired, , but does not speak. Having atways been relieved by the loss of blood, thirteen ounces were taken away. The pulse, which was 94 before the bleeding, rose to 120 . A stimulating injection was given, which procured two copious stools, but appeared to make bin worse; indeed, he seemed as if dying after the second. He continued very restless until eight o'cluck, when he took forty drops of tincture of opium ; and on visiting him at ten, aud again at two in the morning, he was found more quiet, less hot, sensible, and able to answer questions.

Saturday uorning, six o'clock. - Continues much in the same state as at the last visit, except that his water has passed twice involuntarily.

At twelve o'clock, be complained of so much pain in the head, and was so hot, thirsty, and restless, that he was bled to eight ounces, which produced faintness, from which however he soon recovered. His pulse quickened very much after the bleeding, and at six o'clock he was in every respect worse; he is sensible but does not speak. Forty drops of tincture of opium were given, and five grains of Dover's powder, every three hours, which had the effect of procuring a good deal of sleep.

From this time he regularly improved, and by pursuing the same plan, with careful attention to his bowels, he perfectly recovered.

This case occurred many years ago, before the attention of surgeons was directed to the effects of loss of blood on the system. It is very evident that the syinptoms which alarined me so much for the safety of ny patient were aggravated by my treatment, and that if $I$ had not carried bleeding to such an extent, but had given opium and nourishment more freely at an earlier period, I should have spared my patient snuch suffering and myself great anxiety. I consider this a case rescued at the eleventh hour, and attribute my patient's recovery entirely to a hint which I received from an old practitioner, who kindly visited hin with me in the most critical stage of illness, and remarked, that in his day, Bloomtield always directed Dover's powder in all cases of violent injury of the head, and concussion of the brain. In this case I mistook exhaustion and irritation for inflammation-a common error with young and inexperienced practitioners. This is an important point in practice, requiring the nicest discrimination, on which a hasty or injudicious decision often leads to a fatal result.

\section{Case v.}

I was culled in the middle of the night in December, to a young gentleman who had been picked up on the turnpike road, in a complete state of insensibility, bleeding freely from both ears. As he was alone, it was not known how he came there, or how long he Lad lain in that position, but it was subsequently ascertained that he had been drinking too much and had fallen from his horse. I found him totally insensible and benumbed with cold. As soon as warmth was restored, and inmediate danger from the state of collapse was removed, I examined the head with the most minute attention, without being able to detect any external injury. On the following day his pulse had risen considerably, and he became hot and very restless, the insensibility remaining the same. The bleeding from both ears still continued. He was bled from the arm, cold was applied to the head, and purgative medicine administered. There was no improvement in his state on that or the following day. The hæmorrhage froin the ears continued so profuse as to render further general depletion unnecessary, and persisted until the evening of the third day, when it gradually ceased and be became more sensible. Under the use of cold, occasional local bleeding by leeches, Dover's powder, and saline medicine, with perfect quiet, he slowly but completely recovered.

Mr. Abernethy laid it down as an axiom, that hxinorrhage to any considerable degree from the ears was an infullible sign of fracture of the base of the skull, and this case presents an example of the accident which cannot, I imagine, be doubted. Judging from the profuseness of the discharge and its duration, it is reasonable to suppose that the injury was very extensive. It may' therefore be considered a rare instance of recovery from an accident so generally fatal.

Ashley Lodge, Torquay, Junuary 6, 1846.

\section{ON CUTANEOUS DISEASES.}

\section{(Concluded from page 760 of last volume.)}

I.will now conclude these papers with a few observations on-

TRE ATMENT.

General principles.-All inflammatory diseases of the skin must be treated on antiphlogistic principles. The patient should be kept in a uniform cool temperature, avoiding exposure either to heat or cold, and paying particular attention to cleanliness. All stimuli must be rejected, and low diet enforced; acidulated drinks and saline aperients, with tartarized antimony, are indicated. According to the urgency of the symptoms, bleeeding, (general or local,) purging, and mercury, together with alkalies, will, be necessary. The local treatment embraces the use of the warm bath and fomentations, tepid sponging, medicated baths, dilute acids, cold water, \&c.

If the disease suddenly disappear we must stimulate; or if there be debility, support with tonics, \&zc.

Particular remedies. Emetics are often serviceable at the cominencement. General blood-letting is of grêat use in active cases, followed up by leeches; or these alone will sometimes suffice. Mercury in its mildest forms may be given in obstinate cases, as hydrargyrum cum creta, blue or Plummer's pill. Colchicum is a valuable remedy in many cases; I generally combine the wine with salts in mixture. Alkalies are very useful and correct the acidity so common in cutaneous affections-as Liquor Potassæ, Sesqui-Carbonate of Soda, or Magnesia, twice or thrice daily. Stimuli are indicated in sudden disappearance of the eruption, as Liquor Ammoniæ, twice or thrice daily, and warm or mustard baths, or blisters kept on only for a few hours. Tonics in debility, as iron or quinine ; and nutritious diet, as meat, wine, porter, \&c.

To relieve tingling and itching apply a dilute solution of chloride of lime or soda ; dilute acids, as vinegar; prussic acid, (dr. j. to oz. viij, sometimes stronger;) 